\title{
IT PAYS TO MANAGE HEALTH PROTECTION AND SAFETY AT WORK
}

Under European Union directives, employers have responsibilities for the safety and health of their workers. Directive 89/391 provides the general framework for health and safety management, risk identification and prevention. The directive has been implemented in national legislation that may include additional requirements. In the Slovak Republic the health and safety work act 1996 required an employer to identify and to control risks to workers and others. An assessment of risk is nothing more than a careful examination of what, in work could cause harm to people, so that we can weight up whether wehave taken enough precautions or should do more to prevent harm.

Every year about 5,500 people are killed in workplaces across the European Union, with another 4,5 million accidents resulting in more than 3 days absence from work (amounting to around 146 million working days lost). These accidents are estimated to cost the EU about 20 billion Euro. The problem affects all sectors of the economy and is particularly acute in enterprises with less than 50 workers. Accident prevention is a good business. Accidents and occupational accidents can have a major financial impact. Prevention of accidents has more benefits than just reducing damages. Preventing work accidents, occupational injures and diseases not only reduces the costs, but also contributes to improving company performance.

Occupational safety and health can affect company performance in many ways, for instance health workers are more productive and can produce at higher quality. A reduction in work/related accidents and illnesses leads to less sick leave. In turn this results in lower costs and less distruption of production processes.

Equipment and working environment that is optimized to the needs of working processes and that are well maintained lead to higher productivity.

Under European Union directives, employers have responsibilities for the safety and health of their workers. Directive 89/391 provides the general framework for health and safety management, risk identification and prevention. The directive has been implemented in national legislation that may include additional requirements. In the Slovak Republic the health and safety work act 1996 required an employer to identify and to control risks to workers and others.

Employers are required to assess risks and take practical measures to protect the safety and health of their workers, keep accident records, provide information and training, consult employees and cooperate and coordinate measures with contractors. A hierarchy of prevention is set including.
Avoid risks at source

Combat risks at source

Adapt work to the worker

Replace the dangerous with the non dangerous, and

Give collective measures priority over individual measures

Companies should ensure the safety and health of workers in every aspect related to their work. Therefore, employers should take the necessary measures for the safety and health protection of workers, including the prevention of occupational risks and the provision of information and training, and provide the necessary organization and means.

Management control of health and safety is cost -effective, safety pays. The true cost of accident can far outweigh the costs of prevention. Poor control of health and safety will mean pressure from enforcing authorities and payment of the legal penalties. The methods for controlling health and safety risks are the same as for controlling quality and protecting the environment. If you fail to manage health and safety you also risk quality and environmental consequences. An assessment of risk is nothing more than a careful examination of what, in your work could cause harm to people, so that you can weight up whether you have taken enough precautions or should do more to prevent harm. The aim is to make sure that no one gets hurt or becomes ill. Accidents and ill health can ruin lives and affect your business too if output is lost, machinery is damaged, insurance costs increase, or you have to go to court.

Risk assessment involves:

- Identifying hazards - what might go wrong?

- Judging who might be harmed and how seriously, including employees, contractors, the public

- Deciding how likely it is to happen

- Deciding how these risks can be eliminated or reduced - can facilities, work methods, equipment or training be improved?

- Setting priorities for action based on size of risk, numbers affected etc.

\footnotetext{
* Viera Šukalová, Olga Poniščiaková

Department of Economics, F PEDAS, University of Žilina, E-mail: viera.sukalova@fpedas.utc.sk; olga.ponisciakova@fpedas.utc.sk
} 
- Implementing control measures

- Reviewing, to check that control measures are working

- Including employee consultation in the process and providing information on risk assessment results.

\section{It must be done five steps to risk assessment.}

\section{Step 1: Look for the hazards}

If you are doing the assessment yourself, walk around the workplace and look afresh at what could reasonably be expected to cause harm. It is better to concentrate only on significant hazards, which could result in serious harm or affect several people. Also employees or their representatives can tell what they think. They may have noticed thongs, which are not immediately obvious. Manufacturer s instructions or datasheets can also help you spot hazards and put risks in their true perspective.

\section{Step 2: Decide who might be harmed and how}

We can not forget people who may not be in the workplace all the time, e.g. cleaners, visitors, contractors, maintenance personnel, etc. Members of the public, or people sharing the workplace with can be hurt also in some cases.

Step 3: Evaluate the risks arising from the hazards and decide whether existing precautions are adequate or more should be done

Even after all precautions have been taken, usually some risk remains. What you have to decide for each significant hazard is whether this remaining risk is high, medium or low. First, ask yourself whether you have done all the things that the law says you have got to do. Your real aim is to make all risks small by adding to your precautions if necessary. Improving health and safety need not cost a lot. For instance, placing a mirror on a dangerous blind corner to help prevent vehicle accidents, or putting some non/slip material on slipery steps are inexpensive precautions considering the risk. Only use the personal protective equipment when there is nothing else that you can reasonably do.

\section{Step 4:}

The risk assessment should show that

- a proper check was made

- you asked who might be affected

- you dealt with all the obvious significant hazards

- the precautions are reasonable and the remaining risk is low.

The written document has to be kept for future reference, it helps to show that you have done what the law requires.

\section{Step 5:}

Sooner or later you will bring in new machines, substances and procedures which could lead to new hazards. If there is any signif- icant change, you should add to the assessment to take account of new hazards in any case, it is good practice to review your assessment from time to time. Don $t$ amend your assessment for every trivial change, or still more, for each new job, but if a new job introduces significant new hazards of its own, you will want to consider them in their own right and do whatever you need to keep the risks down.

A structured approach to management ensures that risks are fully assessed and that safe methods of work are introduced and followed. Periodic review checks that these measures remain appropriate. A typical management model:

1. Policy - sets commitment, objectives, responsibilities for the organization.

2) Planning - identifies and assesses the risks arising from work activities and how they can be controlled. Activities in the planning process include:

- risk assessment and identification of prevention measures

- identifying the management arrangements and organization needed to exercise control

- identifying training needs

- ensuring that occupational health and safety knowledge, skills and expertise are available

3. Implementation and operation - involves putting plans into practice. This may mean: making changes to the organization and working procedures, working environment, equipment and products used, training management and staff and improving communications.

4. Checking and corrective action - Performance should be monitored. This can be reactive, e.g. using accident recorders or proactive, e.g. by feedback from inspections and audits and from staff surveys.

Accident investigations should identify the inmediate and underlying causes, including management failings. The aim is to ensure that systems and procedures are working and to inmediately take any corrective action needed.

5. Management review and audit - allows checking of the management system s overall performance. External circumstances may have changed, e.g. new legislation has been introduced. There is also an opportunity to look forward, e.g. to changes in business structure, development of new products or management level. Auditing examines weather the policy, organization and systems are actually achieving the right results.

Workers have a right to receive information about the risk to health and safety, preventive measures, first aid and emergency procedures. Employees have duties to co-operate actively with employers preventive measures, following instructions in accordance with training given and taking care of their own and workmates safety and health.

\section{References:}

[1] The health protection and safety work act 1996

[2] http:// europe.osha.eu.int 